This item was submitted to Loughborough's Research Repository by the author.

Items in Figshare are protected by copyright, with all rights reserved, unless otherwise indicated.

\title{
Analysis of supramolecular complexes of 3-methylxanthine with field asymmetric waveform ion mobility spectrometry combined with mass spectrometry
}

\section{PLEASE CITE THE PUBLISHED VERSION}

http://dx.doi.org/10.1007/s13361-016-1351-y

\section{PUBLISHER}

(c) American Society for Mass Spectrometry. Published by Springer Verlag (Germany)

\section{VERSION}

AM (Accepted Manuscript)

\section{PUBLISHER STATEMENT}

This work is made available according to the conditions of the Creative Commons Attribution-NonCommercialNoDerivatives 4.0 International (CC BY-NC-ND 4.0) licence. Full details of this licence are available at: https://creativecommons.org/licenses/by-nc-nd/4.0/

\section{LICENCE}

CC BY-NC-ND 4.0

\section{REPOSITORY RECORD}

Arthur, Kayleigh L., G.A. Eiceman, James C. Reynolds, and Colin S. Creaser. 2019. "Analysis of Supramolecular Complexes of 3-methylxanthine with Field Asymmetric Waveform Ion Mobility Spectrometry Combined with Mass Spectrometry". figshare. https://hdl.handle.net/2134/20582. 
Analysis of supramolecular complexes of 3-methylxanthine with field asymmetric waveform ion mobility spectrometry combined with mass spectrometry

Kayleigh L. Arthur ${ }^{1}$, Gary A. Eiceman ${ }^{1,2}$, James C. Reynolds ${ }^{1 *}$ and Colin S. Creaser ${ }^{1 *}$

${ }^{1}$ Centre for Analytical Science, Department of Chemistry, Loughborough University, Loughborough, LE11 3TU, UK

${ }^{2}$ Department of Chemistry and Biochemistry, MSC 3C, P.O. Box 3001, New Mexico State University, Las Cruces, NM 88003-8001, USA

Running title: ESI-FAIMS-MS of 3-methylxanthine complexes

Address reprint requests to James C. Reynolds and Colin S. Creaser; Address: Centre for Analytical Science, Chemistry Department, Loughborough University, Loughborough, Leicestershire, LE11 3TU, UK; Tel: +44 (0) 1509 222590, +44 (0) 1509 222552; Fax: +44 (0) 1509 223925; Email: : J.C.Reynolds@lboro.ac.uk, C.S.Creaser@lboro.ac.uk. 


\begin{abstract}
Miniaturised field asymmetric waveform ion mobility spectrometry (FAIMS), combined with mass spectrometry (MS), has been applied to the study of self-assembling, non-covalent supramolecular complexes of 3-methylxanthine (3-MX) in the gas phase. 3-MX forms stable tetrameric complexes around an alkali metal $\left(\mathrm{Na}^{+}, \mathrm{K}^{+}\right)$or ammonium cation, to generate a diverse array of complexes with single and multiple charge states. Complexes of $(3-\mathrm{MX})_{n}$ observed include: singly charged complexes where $n=1-8$ and 12 and doubly charged complexes where $n=12-24$. The most intense ions are those associated with multiples of tetrameric units, where $n=4,8,12,16,20,24$. The effect of dispersion field on the ion intensities of the self-assembled complexes indicates some fragmentation of higher order complexes within the FAIMS electrodes (in-FAIMS dissociation), as well as in-source collision induced dissociation within the mass spectrometer. FAIMS-MS enables charge state separation of supramolecular complexes of $3-\mathrm{MX}$ and is shown to be capable of separating species with overlapping mass-to-charge ratios. FAIMS selected transmission also results in an improvement in signal-to-noise ratio for low intensity complexes and enables the visualisation of species undetectable without FAIMS.
\end{abstract}

\title{
Keywords
}

Field asymmetric waveform ion mobility spectrometry, FAIMS, mass spectrometry, self-assembling complexes, dissociation, in-source CID, charge state separation 


\section{Introduction}

Self-assembling supramolecular complexes of simple molecules are of interest in a wide variety of fields [1] including structural biology [2], self-assembling membranes [3], therapeutic delivery systems [4], nanostructures [5-7], electrochemistry [8] and supramolecular technology [9]. 3Methylxanthine (3-MX) is an example of a small molecule that can form stable non-covalently bound supramolecular complexes in the gas phase [10]. 3-MX has been shown to self-assemble in the presence of alkali metals and ammonium ions to form clusters around a stabilising cation, as shown in Structure 1; the 3-MX purine base contains both hydrogen bond donor $(\mathrm{NH}(1)$ and $\mathrm{O}(2))$ and acceptor $(\mathrm{NH}(7)$ and $\mathrm{O}(6))$ groups [11-13].

3-MX is a purine derivative and a metabolite of caffeine and theophylline $[14,15]$, and has been monitored biologically in urine and plasma by liquid chromatographic methods [16-19]. Guanine is a related purine base structure that self-assembles into tetrad structures in biological systems (Gquadruplexes) to form complexes that have been well characterised, theoretically and experimentally [2,20-24]. Other related purine bases, such as xanthine and uric acid derivatives, have shown to similarly self-assemble into non-covalently bound tetrameric species $[11,25,26]$. Gquadruplexes are of significant interest due to their formation in vivo at telomeres and their potential application as anticancer drug targets. Purine bases such as xanthine and uric acid are an intermediate and the end product respectively of purine metabolism, which are of interest in the analysis of metabolites as elevated levels can lead to a number of diseases and conditions [25].

Ion mobility spectrometry (IMS) is an ion separation technique that distinguishes ions based upon their velocity as they migrate through a buffer gas under the influence a weak electric field, where ion mobility is determined by the ratio of the velocity of the ion to the applied electric field. Under strong electric fields the mobility of an ion has a non-linear dependence on the electric field strength, and this forms the basis of field asymmetric waveform ion mobility spectrometry (FAIMS), which separates ions based upon the compound-dependent differences in their mobilities in alternating high and low electric fields. In a FAIMS device, ions pass between two electrodes with an applied asymmetric RF waveform known as the dispersion field (DF), under which the ions 
experience alternating low and high fields, resulting in a net displacement towards one of the electrodes [27-31]. A small DC voltage, known as the compensation field (CF), is superimposed on the DF to transmit selected analytes by off-setting the net displacement through the device [32-34] The DF and CF (unit of Townsend (Td) where $1 \mathrm{Td}=10^{-17} \mathrm{~V} \mathrm{~cm}^{-2}$ ) can be scanned over a range to produce a two-dimensional FAIMS spectrum or set statically to transmit ions of interest. The separation of ions based on their mobility under low $(<10 \mathrm{Td})$ and high ( $>100 \mathrm{Td})$ field conditions has a high level of orthogonality to mass-to-charge $(\mathrm{m} / \mathrm{z})$ separation in mass spectrometry (MS) allowing for the hyphenation of ESI-FAIMS-MS [35].

3-MX has been studied by ESI-MS and nuclear magnetic resonance by Szolomájer et al. [10]; mass spectral data for a single tetrameric complex of 3-MX (or tetrad) and an octameric species composed of two parallel tetrads were reported. Here we report a study of using ESI combined with a prototype FAIMS device and orthogonal acceleration time-of-flight (TOF) MS, to investigate noncovalently bound, supramolecular complexes of $(3-M X)_{n}$. Singly charged complexes up to $n=12$, doubly charged complexes up to $n=24$, and a range of intermediate complexes are observed. This study demonstrates the capability of FAIMS to aid in the analysis of non-covalent supramolecular complexes by mass spectrometry.

\section{Experimental}

\section{Sample Preparation}

HPLC grade methanol, water, and analytical grade sodium hydroxide and ammonium acetate were purchased from Fisher Scientific (Loughborough, UK). 3-MX was purchased from Sigma-Aldrich (Gillingham, UK). 3-MX (0.5 mM) solutions in 60:40 v/v methanol:water were prepared with two different modifiers (1 $\mathrm{mM}$ each): sodium hydroxide and ammonium acetate to promote adduct clusters. Standard solutions of 3-MX were analysed by direct syringe infusion. 


\section{ESI-MS and ESI-FAIMS-MS Instrumentation}

ESI-FAIMS-MS analyses were carried out using an Agilent 6230 TOF MS (Agilent Technologies, UK) fitted with a prototype miniaturised chip-based FAIMS (Owlstone Ltd., Cambridge, UK), which has been described in detail elsewhere $[33,36,37]$. The FAIMS device was located behind the modified spray shield of the Jet Stream ESI source, in front of the mass spectrometer inlet capillary, and consists of multiple parallel planar electrode channels (100 $\mu \mathrm{m}$ electrode gap) with a short trench length $(78.1 \mathrm{~mm})$ and ion path length $(700 \mu \mathrm{m})$.

Direct infusion ESI-MS experiments were carried out in positive ionisation mode using a $10 \mu \mathrm{L} \mathrm{min}^{-1}$ sample infusion rate from a syringe pump. The ESI nebuliser pressure was set to 30 psig with a sheath gas $\left(\mathrm{N}_{2}\right)$ flow of $10 \mathrm{~L} \mathrm{~min}^{-1}$ at $200{ }^{\circ} \mathrm{C}$, with the nozzle voltage set to $2000 \mathrm{~V}$. The capillary voltage was set to $3500 \mathrm{~V}$ and the drying gas $\left(\mathrm{N}_{2}\right)$ flow to $8 \mathrm{~L} \mathrm{~min}^{-1}$ at $150{ }^{\circ} \mathrm{C}$. The MS scan rate was 10 scans per $s$ in the mass range $\mathrm{m} / \mathrm{z} 90-2200$, with a fragmentor voltage of $150 \mathrm{~V}$.

ESI-FAIMS-MS experiments were performed by direct syringe infusion of 3-MX solutions and by scanning of the FAIMS DF and CF to investigate the transmission of singly, doubly and multiply charged 3-MX clusters through the FAIMS device. The DF was stepped from 194 to 323 Td (12 steps) and the CF was scanned from -2 to $+5 \mathrm{Td}$, at a rate of $0.1 \mathrm{Td} \mathrm{s}^{-1}$ (140 steps), to perform a two-dimensional scan of the FAIMS parameters.

\section{Results and Discussion}

The self-assembly of 3-MX results in a complex ESI mass spectrum when a solution of 3-MX is infused in 60:40 v/v methanol:water with $1 \mathrm{mM}$ ammonium acetate (Figure 1). A range of noncovalent clusters with different cations are observed in the gas phase, in agreement with Szolomájer et al. [10]. When ammonium acetate is added as a solvent modifier, abundant peaks correspond to tetrameric species with alkali metal and ammonium cations (Figure 1 (a)); for example [(3-MX $\left.)_{4}+\mathrm{NH}_{4}\right]^{+}(\mathrm{m} / \mathrm{z} 682)$, [(3-MX $\left.)_{4}+\mathrm{Na}\right]^{+}(\mathrm{m} / \mathrm{z} 687)$ and $\left[(3-\mathrm{MX})_{4}+\mathrm{K}\right]^{+}(\mathrm{m} / \mathrm{z} 703)$. The mass spectrum is characterised by many singly (Figure $1(\mathrm{a})$ ), doubly (Figure 1 (b) $-(\mathrm{d})$ ) and multiply 
(Figure $1(d)$ ) charged species, making it difficult to identify which species are present because of the overlapping isotopic patterns.

The use of sodium hydroxide as a solvent modifier results in a simplified mass spectrum dominated by singly charged sodiated adducts as shown in Figure $1(\mathrm{e})$, The base peak in the spectrum is the $\left[(3-\mathrm{MX})_{4}+\mathrm{Na}\right]^{+}$ion at $\mathrm{m} / \mathrm{z} 687.19$, with the second most intense response corresponding to the [(3$\left.\mathrm{MX})_{8}+\mathrm{Na}\right]^{+}$ion at $\mathrm{m} / \mathrm{z}$ 1351.39. Monomer, dimer and trimer sodiated complexes are observed with lower intensities at $\mathrm{m} / \mathrm{z} 189.04,355.09$ and 521.14 respectively, suggesting that the tetrameric based complexes are more stable than non-tetrameric structures. Complexes of $(3-\mathrm{MX})_{n}$ observed in the presence of sodium ions include: singly charged tetrameric complexes $\left[(3-\mathrm{MX})_{n}+\mathrm{xNa}-\mathrm{yH}\right]^{+}(\mathrm{x}-$ $y=1$ for $x=1-5, y=0-4)$ where $n=4,8$, and 12 ; doubly charged tetrameric complexes [(3$\left.M X)_{n}+x N a-y H\right]^{2+}(x-y=2$ for $x=2-10, y=0-8)$ where $n=12,16,20$, and 24; and a range of triply charged complexes corresponding to $\mathrm{n}=32$ in the region $m / z$ 1815-1850, for example [(3$\left.\mathrm{MX})_{32}+6 \mathrm{Na}-3 \mathrm{H}\right]^{3+}$. Intermediate non-tetrameric complexes of low intensity are also observed that correspond to singly charged complexes where $n=1-3$ and $5-7$, and doubly charged non-tetrameric complexes where $n=13-15$ and $17-23$. The focus of this study was on the 3-MX monomer and singly charged tetrameric complexes of $3-\mathrm{MX}$ with sodium: [(3-MX)+Na] $]^{+}(\mathrm{m} / \mathrm{z}$ 189.04), [(3$\left.\left.\mathrm{MX})_{4}+\mathrm{Na}\right]^{+}(m / z \text { 687.18), [(3-MX) })_{8}+\mathrm{Na}\right]^{+}\left(\mathrm{m} / z \text { 1351.38) and [(3-MX) }{ }_{12}+2 \mathrm{Na}-\mathrm{H}\right]^{+}(\mathrm{m} / \mathrm{z} 2037.55)$.

The sodiated 3-MX clusters present in the ESI-MS spectrum (Figure 1) were also observed using ESI-FAIMS-MS. This demonstrates that supramolecular complexes of 3-MX may be transmitted through the FAIMS device in the presence of the alternating high and low electric fields and at a temperature of $150{ }^{\circ} \mathrm{C}$ (standalone FAIMS is routinely used at much lower temperatures, i.e. atmospheric temperature) [38]. The hyphenation of FAIMS with MS allows ions of a single $\mathrm{m} / \mathrm{z}$ to be selected as the CF is scanned at a fixed DF giving the characteristic FAIMS CF spectrum of each ion. Alternatively, a FAIMS three-dimensional representation of DF, CF and intensity can be obtained by sweeping the DF (194-323 Td, in steps of $10 \mathrm{Td}$ ) and CF (-2-5 Td, in steps of $0.05 \mathrm{Td})$ to generate a heat map (or contour plot), where DF is plotted against CF and the intensity is represented by a colour scale [39]. The ESI-FAIMS-MS heat maps are plotted for mass-selected 
ions in order to provide a way to observe the behaviour of selected ions transmitted through the FAIMS device, and aid in the selection of parameters to resolve ions of interest [39].

The 3-MX monomeric species is the building block of all of the complexes in the mass spectrum for 3-MX (Figure 1). Figure 2 shows the FAIMS characteristics of the 3-MX monomer $\left([(3-\mathrm{MX})+\mathrm{Na}]^{+}\right.$, $m / z$ 189.04) at three different fragmentor voltages on the MS, which is applied in the intermediate pressure region of the MS interface, with the FAIMS swept between DF 180-300 Td (steps of $10 \mathrm{Td}$ ) and CF $-2-5 \mathrm{Td}$ (steps of $0.05 \mathrm{Td}$ ). The monomer ion observed at DF $200 \mathrm{Td}$ and fragmentor voltage of $150 \mathrm{~V}$ (Figure 2 (a) black solid line, and Figure 2 (b)), is an intense peak centred around CF - $0.05 \mathrm{Td}$ can be observed at DF values up to $260 \mathrm{Td}$, with a secondary peak centred around CF $0.65 \mathrm{Td}$ at DF $200 \mathrm{Td}$ in Figure 2 (a). This secondary peak can be observed to reduce in intensity as the fragmentor voltage is lowered from $150 \mathrm{~V}$ to $100 \mathrm{~V}$ (Figure 2 (a) grey dotted line, and Figure 2 (c)), and when lowered to $50 \mathrm{~V}$ (Figure 2 (a) grey solid line, and Figure 2 (d)). The peak is not present in the CF spectrum at DF $200 \mathrm{Td}$ and little remains in the heat map at $50 \mathrm{~V}$. The overlaid CF spectra for the 3-MX dimer $\left(\left[(3-\mathrm{MX})_{2}+\mathrm{Na}\right]^{+} \mathrm{m} / \mathrm{z} 355.09\right)$, in Figure 2 (b) black dotted line, is also centred around CF $0.65 \mathrm{Td}$ at DF $200 \mathrm{Td}$, showing a strong correlation to the secondary peak in the CF spectra of the 3-MX monomer. This suggests that the dimer was transmitted through the FAIMS electrodes intact and fragmented in the MS interface by in-source collision induced dissociation (insource $\mathrm{CID}$ ) at $150 \mathrm{~V}$ post-FAIMS separation, resulting in the two peaks evident in the CF spectra and the FAIMS heat maps for the $\mathrm{m} / \mathrm{z} 189.04[36,40]$. This is further supported by the mass spectra (Supplementary Figure 1) extracted at the optimum FAIMS transmission conditions for the two peaks (DF $200 \mathrm{Td}, \mathrm{CF}-0.05 \mathrm{Td}$ and $0.65 \mathrm{Td}$ ) at each of the three fragmentor voltages, showing the $\mathrm{m} / \mathrm{z} 189$ ion of the 3-MX monomer present in the mass spectra at CF $0.65 \mathrm{Td}$ at $150 \mathrm{~V}$, which decreases at $100 \mathrm{~V}$ and is not present at $50 \mathrm{~V}$. In each of the heat maps for the 3-MX monomer (Figure 2 (b), (c) and (d)), the intensity reduces sharply as the DF increases above 240 Td resulting from a greater number and velocity of collisions due to field heating at higher DFs [28,32].

The change in CF for transmission of the $(3-M X)_{n}(n=4,8,12)$ tetrameric complexes, in Figure 3 (a), follows a trend with increased distance from $0 \mathrm{Td}$ in the order: $\left[(3-\mathrm{MX})_{12}+2 \mathrm{Na}-\mathrm{H}\right]^{+}(1.15 \mathrm{Td})<$ 
$\left[(3-\mathrm{MX})_{8}+\mathrm{Na}\right]^{+}(1.70 \mathrm{Td})<\left[(3-\mathrm{MX})_{4}+\mathrm{Na}\right]^{+}(2.05 \mathrm{Td}) ;$ i.e. the difference in CF from $0 \mathrm{Td}$ decreases as the size of the complex increases. The increased distance from $0 \mathrm{Td}$ can be attributed to increased differences in mobility between electric field extremes. The overlap of the CF spectra and near even distribution of this trend suggests an incremental effect of the FAIMS conditions of the tetrameric based structures of these singly charged complexes of 3-MX, possibly indicating an influence of structure and size, and suggests a relationship with the number of layers in the stacked assembly $[5,10]$.

The single tetramer structure $\left(\left[(3-\mathrm{MX})_{4}+\mathrm{Na}\right]^{+}, m / z\right.$ 687.18) was observed to be stable through the FAIMS device at all DFs up to 300 Td (Figure 3 (a) solid black line and (b)), indicated by the symmetrical profile that retains a constant peak width, with a slight fall in intensity at the higher DFs up to $323 \mathrm{Td}$. In contrast, the $\left[(3-\mathrm{MX})_{12}+2 \mathrm{Na}-\mathrm{H}\right]^{+}(\mathrm{m} / z$ 2037.55) ion has a broad, unsymmetrical profile at all DFs (Figure 3 (c)) compared to the single tetramer complex (Figure 3 (b)). This unsymmetrical broadening of the $\left[(3-\mathrm{MX})_{12}+2 \mathrm{Na}-\mathrm{H}\right]^{+}$profile (Figure $3(\mathrm{c})$ ) at DFs above $270 \mathrm{Td}$, could be due to a combination of factors such as: signal instability due to the low intensity of the ion; a higher probability of a distribution of conformations for this larger complex; or the dissociation of higher complexes during transmission through the FAIMS electrodes. Evidence for in-FAIMS dissociation is provided in the mass spectra, shown in Supplementary Figure 2, extracted at DF 323 Td and CF 2.70 Td, corresponding to the high CF tailing edge of the asymmetrical peak of the [(3$\left.\mathrm{MX})_{12}+2 \mathrm{Na}-\mathrm{H}\right]^{+}$ion (Figure $3(\mathrm{a})$ ). In addition to the singly charged $\mathrm{m} / \mathrm{z} 2037.55$ ion in the mass spectrum (Supplementary Figure 2 (b)), abundant species include higher ordered doubly charged ions of $\mathrm{n}=16$ and 20 in the regions $m / z 1362-1395$ and $m / z 1694-1716$ respectively. This suggests that the electric field strengths experienced by ions in the FAIMS (up to $60 \mathrm{kV} \mathrm{cm}^{-1}$ ) may cause higher ordered and doubly charged complexes, such as $n=16,20$ and 24 (formed in the ESI source) to dissociate to yield singly charged $\mathrm{m} / \mathrm{z} 2037.55$ ions during transmission through the FAIMS electrodes (the relative fragility of the structures can be observed via a tandem MS analysis shown in Supplementary Figure 3). 
The singly charged octameric complex, $\left[(3-\mathrm{MX})_{8}+\mathrm{Na}\right]^{+}$(Figure $\left.4(\mathrm{a})\right)$, is observed to have a very stable and symmetrical profile even up to the highest DF values, similar to the single tetramer structure $\left[(3-\mathrm{MX})_{4}+\mathrm{Na}\right]^{+}$(Figure $\left.3(\mathrm{~b})\right)$, but the reduction in ion intensity as the DF increases, expected due to increased field heating and scattering of ions through the FAIMS device at higher DFs, is not observed. The CF for maximum transmission of $\left[(3-\mathrm{MX})_{8}+\mathrm{Na}\right]^{+}$increases from $0.35 \mathrm{Td}$ (DF $194 \mathrm{Td}$ ) to $1.70 \mathrm{Td}$ (DF $323 \mathrm{Td}$ ), an increase of $1.35 \mathrm{Td}$. In contrast, a doubly charged complex $\left[(3-\mathrm{MX})_{16}+3 \mathrm{Na}-\mathrm{H}\right]^{2+}$ (Figure $\left.4(\mathrm{~b})\right)$, whilst having a symmetrical profile, is much more affected by the electric fields with the CF for maximum transmission increasing from 0.65 Td (DF $194 \mathrm{Td}$ ) to $2.85 \mathrm{Td}$ (DF $323 \mathrm{Td}$ ), an increase of $2.20 \mathrm{Td}$, and the intensity starts to decrease significantly at DF $260 \mathrm{Td}$ and above. The intensities of $\left[(3-\mathrm{MX})_{8}+\mathrm{Na}\right]^{+}$and $\left[(3-\mathrm{MX})_{16}+3 \mathrm{Na}-\mathrm{H}\right]^{2+}$ at DF values in the range $180-$ $300 \mathrm{Td}$ at the lowest fragmentor voltage of $50 \mathrm{~V}$ (Supplementary Figure 4), show the expected decrease in the intensity for the doubly charged $\left[(3-\mathrm{MX})_{16}+3 \mathrm{Na}-\mathrm{H}\right]^{2+}$ ion at higher DFs as seen from Figure $4(\mathrm{~h})$. However, the intensity of $\left[(3-\mathrm{MX})_{8}+\mathrm{Na}\right]^{+}$ion shows an unexpected overall increase as the DF increases. We believe that this increase in intensity of the singly charged 3-MX octameric complex is evidence that the higher ordered and more highly charged species, such as the doubly charged $\left[(3-\mathrm{MX})_{16}+3 \mathrm{Na}-\mathrm{H}\right]^{2+}$, may dissociate in the FAIMS device into the smaller singly charged complexes, such as $\left[(3-\mathrm{MX})_{8}+\mathrm{Na}\right]^{+}$.

The isotope pattern provides a source of identification for singly or multiply charged species in mass spectrometry, but will not separate isobaric ions of different charge states. However, ESI-FAIMS-MS allows for the separation of ions based upon compound-dependent differences in high and low field mobility as a result of charge state $[33,36,41]$. FAIMS separation may therefore be used to suppress or enhance the transmission of singly or multiply charged ions selectively. The significance of this becomes apparent for overlapping isotopic patterns of singly and doubly charged species, such as $(3-M X)_{8}$ and $(3-M X)_{16}$ in the range $m / z 1300-1400$ in Figure 4 (c), which cannot be resolved by the reflectron TOF mass analyser alone. However, the singly charged $\left[(3-\mathrm{MX})_{8}+2 \mathrm{Na}-\mathrm{H}\right]^{+}$ion $(\mathrm{m} / \mathrm{z}$ 1373.37) is resolved from the corresponding doubly charged $\left[(3-\mathrm{MX})_{16}+4 \mathrm{Na}-2 \mathrm{H}\right]^{2+}$ ion with the same $\mathrm{m} / \mathrm{z}$ by FAIMS (Figure $4(\mathrm{~d})$ ). FAIMS-selected transmission of the appropriate charge state is shown 
in Figure 4 (e) and (f) at CF $1.70 \mathrm{Td}$ and $2.85 \mathrm{Td}$ respectively (DF $323 \mathrm{Td}$ ), resulting in the ESIFAIMS-MS separation of overlapping singly and doubly charged isobaric 3-MX species in the mass spectrum. The most abundant octameric species with a single sodium cation $\left(\left[(3-\mathrm{MX})_{8}+\mathrm{Na}\right]^{+}\right)$at $\mathrm{m} / \mathrm{z}$ 1351.39 also demonstrates the ability of FAIMS to increase the signal-to-noise ratio (S:N), by 2.8 times in Figure 4 (e) compared to the FAIMS off mass spectrum in Figure 4 (c), and also the ability to filter out this highly abundant singly charged species to reveal that there is no evidence of a [(3$\left.\mathrm{MX})_{16}+2 \mathrm{Na}\right]^{2+}$ complex which would have the same $m / z$ (Figure 4 (f)). A 2-3 fold enhancement of the S: $N$ was observed for all of the complexes in Figure 4 (e) and (f), compared to Figure 4 (c), as a result of the removal of background noise from the doubly and singly charged species for Figure 4 (e) and (f) respectively.

In this study of 3-MX complexes, a second type of heat map of $m / z$ vs. CF at a particular DF (instead of DF vs. CF at a particular $\mathrm{m} / \mathrm{z}$, as shown in Figure 2 and Figure 3) provides an alternative view of selected ions. Figure $4(\mathrm{~g})$ is an example of such a plot, for $m / z$ vs. CF at DF $323 \mathrm{Td}$ in the region $\mathrm{m} / \mathrm{z}$ 1373-1376, which shows the FAIMS separation of the two isobaric species of $\mathrm{m} / \mathrm{z}$ 1373.37 which correspond to the singly and doubly charged species $\left[(3-\mathrm{MX})_{8}+2 \mathrm{Na}-\mathrm{H}\right]^{+}$and $[(3-$ $\left.M X)_{16}+4 \mathrm{Na}-2 \mathrm{H}\right]^{2+}$. These isobaric singly and doubly charged species at $\mathrm{m} / \mathrm{z} 1373.37$ can also be plotted as a heat map of DF vs. CF at all DFs, Figure 4 (h) which shows an intense peak corresponding to the singly charged $\left[(3-\mathrm{MX})_{8}+2 \mathrm{Na}-\mathrm{H}\right]^{+}$and a secondary peak that begins to separate from the main intense peak at DF $240 \mathrm{Td}$ and above. This heat map can be compared to those which are either singly or doubly charged with no corresponding peak present, such as those of $\mathrm{m} / \mathrm{z} 1351.38$ and 1362.38 (Figure 4 (a) and (b)), demonstrating the similar profiles of the singly and doubly charged complexes.

The ESI-mass spectrum of 3-MX with sodium hydroxide as the solvent modifier (Figure $1(\mathrm{e})$ ) is dominated by tetrameric complexes and the transmission of some lower abundance non-tetrameric 3-MX isobaric species can be masked by these prominent ions (Figure 5). For example, in the mass spectrum of 3-MX in the region $m / z$ 1016-1026 without FAIMS applied (Figure 5 (a)), the peak at $\mathrm{m} / \mathrm{z} 1019.3$ could correspond to $\left[(3-\mathrm{MX})_{6}+\mathrm{Na}\right]^{+}$or $\left[(3-\mathrm{MX})_{12}+2 \mathrm{Na}\right]^{2+}$, though the isotope pattern 
suggests that only the doubly charged tetrameric species is present. However, comparison of the FAIMS peaks for the first two isotopes of this species (Figure 5 (b)) at $m / z 1019.28$ and 1019.78 shows a small shoulder is observed at the low CF edge of the peak for $\mathrm{m} / \mathrm{z} 1019.28$. Careful selection of the FAIMS DF and CF makes it possible to filter out the (35 times) more abundant doubly charged species in order to selectively transmit the singly charged $\left[(3-\mathrm{MX})_{6}+\mathrm{Na}\right]^{+}$ion (Figure 5 (c)); without FAIMS separation it was not possible to determine the presence of this hexameric complex of $3-\mathrm{MX}$, whilst the tetrameric doubly charged $\left[(3-\mathrm{MX})_{12}+2 \mathrm{Na}\right]^{2+}$ dominates the mass spectrum. Also, by selecting the FAIMS at the maximum CF for transmission for $\mathrm{m} / \mathrm{z} 1019.3$ ([(3$\left.\mathrm{MX})_{12}+2 \mathrm{Na}\right]^{2+}$ ) at DF $216 \mathrm{Td}$, the $\mathrm{S}: \mathrm{N}$ is doubled by reducing background noise in the mass spectrum (Figure $5(d)$ ).

The ability of FAIMS to investigate self-assembling supramolecular complexes of 3-MX doped with sodium has been demonstrated. However, ESI-FAIMS-MS analysis can also be used to investigate complexes of 3-MX with different stabilising cations $\mathrm{NH}_{4}^{+}, \mathrm{Na}^{+}$and $\mathrm{K}^{+}$(Supplementary Figure 5) whose FAIMS conditions have been shown to vary dependent on cation. A combination of these varying FAIMS conditions and charge state separation has been utilised to identify heterocationised complexes of 3-MX (Figure 6). In the region $\mathrm{m} / \mathrm{z} 1340-1450$, a range of both singly and doubly charged complexes with different stabilising cations can be identified using ESI-FAIMS-MS that were previously hidden using ESI-MS alone. Figure 6 shows an example of how FAIMS can be used to separate these isobaric compounds of different charge state by examining the FAIMS CF spectra for $m / z 1370.4$ (Figure 6 (a)). The mass spectral peak for $m / z 1370.4$ without FAIMS applied (Figure $6(\mathrm{~b}))$ is an overlap of the more abundant $\left[(3-\mathrm{MX})_{8}+\mathrm{K}\right]^{+}$isotope peaks and a hidden doubly charged ion. Careful selection of the CF maxima of the two peaks in the FAIMS spectra (Figure 6 (a)) and extraction of the mass spectra (Figure 6 (c) and (d)) allows for the separation of the isobaric abundant singly charged complex, $\left[(3-\mathrm{MX})_{8}+\mathrm{K}\right]^{+}$, and the doubly charged hetero-cationic complex, corresponding to $\left[(3-\mathrm{MX})_{16}+2 \mathrm{Na}+\mathrm{K}-\mathrm{H}\right]^{2+}$.

Complexes with multiple cations, both homo- and hetero-cationised complexes, appear to be stable with sodium cations even with ammonium acetate as the modifier. Singly charged octameric homo- 
cation complexes of 3-MX with up to five $\mathrm{Na}^{+}$were observed (DF $323 \mathrm{Td}$, CF $1.65 \mathrm{Td}$ ), while only $\left[(3-\mathrm{MX})_{8}+\mathrm{NH}_{4}\right]^{+}$and $\left[(3-\mathrm{MX})_{8}+\mathrm{K}\right]^{+}$were observed for $\mathrm{NH}_{4}{ }^{+}$and $\mathrm{K}^{+}$. Furthermore, the hetero-cation complexes with $\mathrm{Na}^{+}+\mathrm{K}^{+}$were more abundant than the $\mathrm{NH}_{4}^{+}+\mathrm{Na}^{+}$and $\mathrm{NH}_{4}^{+}+\mathrm{K}^{+}$complexes, with a range of $\mathrm{Na}^{+}+\mathrm{K}^{+}$complexes observed in the region $m / z$ 1340-1450, for example [(3$\left.\mathrm{MX})_{8}+3 \mathrm{Na}+\mathrm{K}-3 \mathrm{H}\right]^{+}(\mathrm{DF} 323 \mathrm{Td}, \mathrm{CF} 1.65 \mathrm{Td})$ and $\left[(3-\mathrm{MX})_{16}+2 \mathrm{Na}+2 \mathrm{~K}-2 \mathrm{H}\right]^{2+}(\mathrm{DF} 226 \mathrm{Td}, \mathrm{CF} 0.85 \mathrm{Td})$. Hetero-cation complexes with all three cations were also observed, with very low intensities, that correspond to $\left[(3-\mathrm{MX})_{8}+\mathrm{NH}_{4}+\mathrm{Na}+\mathrm{K}-2 \mathrm{H}\right]^{+} \quad(\mathrm{m} / z \quad 1406.36 ; \quad \mathrm{DF} 323 \quad \mathrm{Td}, \quad \mathrm{CF} 2.75 \mathrm{Td}), \quad[(3-$ $\left.\mathrm{MX})_{16}+\mathrm{NH}_{4}+2 \mathrm{Na}+\mathrm{K}-2 \mathrm{H}\right]^{2+}(\mathrm{m} / \mathrm{z}$ 1378.87; DF $313 \mathrm{Td}, \mathrm{CF} 2.60 \mathrm{Td}),\left[(3-\mathrm{MX})_{16}+3 \mathrm{NH}_{4}+\mathrm{Na}+2 \mathrm{~K}-4 \mathrm{H}\right]^{2+}$ $(\mathrm{m} / \mathrm{z}$ 1403.88; DF $216 \mathrm{Td}$, CF $0.80 \mathrm{Td})$, and $\left[(3-\mathrm{MX})_{16}+\mathrm{NH}_{4}+3 \mathrm{Na}+2 \mathrm{~K}-4 \mathrm{H}\right]^{2+}(\mathrm{m} / \mathrm{z}$ 1408.84; DF 302 Td, CF 2.30 Td).

\section{Conclusion}

Miniaturised chip-based FAIMS combined with TOF MS has been applied to the study of selfassembling supramolecular non-covalent complexes of 3-MX. Non-covalently bound supramolecular complexes are shown to be able to successfully traverse the FAIMS device, but at high DFs there is evidence for in-FAIMS dissociation of higher ordered complexes may be observed. Singly charged 3-MX complexes of a tetrameric structure were shown to have different CF values for maximum transmission, with CF decreasing with increasing complex size. FAIMS selection prior to mass analysis allows the separation of charge states of 3-MX complexes. Singly charged tetrameric complexes were found to be stable through the FAIMS device, even up to the highest DF values, whilst the doubly charged tetrameric species show a clear decline in intensity at higher CF values as the DF increases than singly charged 3-MX complexes. FAIMS pre-selection allows complexes that were previously concealed by more abundant overlapping isobaric species to be observed, further highlighting the complexity and depth of information that ESI-FAIMS-MS analysis can unravel in the study of these supramolecular complexes. ESI-FAIMS-MS has also been applied to an array of supramolecular non-covalent complexes of 3-MX with multiple cations present, and shown to aid in the identification of hetero-cation complexes. The hyphenation of ESI- 
FAIMS-MS has shown the potential to aid in the deconvolution of complicated mass spectra of other supramolecular non-covalent complexes.

\section{Acknowledgements}

The authors would like to thank Owlstone Ltd., Agilent Technologies and Loughborough University for financial support. We also thank Owlstone Ltd. and Agilent Technologies for the provision of instrumentation. 


\section{References}

1. Lehn, L. M.: Toward complex matter: Supramolecular chemistry and self-organization. PNAS 99, 4763-4768 (2002)

2. Lawrence, D. S., Jiang, T., Levett, M.: Self-assembling supramolecular complexes. Chem. Rev. 95, 2229-2260 (1995)

3. Capito, R. M., Azevedo, H. S., Velichko, Y. S., Mata, A., Stupp, S. I.: Self-assembly of large and small molecules into hierarchically ordered sacs and membranes. Science 319, 1812-6 (2008)

4. Branco, M. C., Schneider, J. P.: Self-assembling materials for therapeutic delivery. Acta Biomater. 5, 817-831 (2009)

5. Ciesielski, A., Haar, S., Benyei, A., Paragi, G., Guerra, C. F., Bickelhaupt, F. M., Masiero, S., Szolomajer, J., Samori, P., Spada, G. P., Kovacs, L.: Self-assembly of N3-substituted xanthines in the solid state and at the solid-liquid interface. Langmuir 29, 7283-7290 (2013)

6. Lin, Y., Boker, A., He, J., Sill, K., Xiang, H., Abetz, C., Li, X., Wang, J., Emrick, T., Long, S., Wang, Q., Balazs, A., Russell, T. P.: Self-directed self-assembly of nanoparticle/copolymer mixtures. Nature 434, 55-59 (2005)

7. Barbera, J., Donnio, B., Gehringer, L., Guillon, D., Marcos, M., Omenat, A., Serrano J. L.: Selforganization of nanostructured functional dendrimers. J. Mater. Chem. 15, 4093-4105 (2005)

8. Tirado, J. D., Acevedo, D., Bretz, R. L., Abruna H. D.: Adsorption dynamics of electroactive selfassembling molecules. Langmuir 10, 1971-1979 (1994)

9. Parviz, B. A., Ryan, D., Whitesides, G. M.: Using self-assembly for the fabrication of nano-scale electronic and photonic devices. \{IEEE\} Trans. Adv. Packag. 26, 233-241 (2003)

10. Szolomajer, J., Paragi, G., Batta, G., Guerra, G. F., Bickelhaupt, F. M., Kele, Z., Padar, P., Kupihar, Z., Kovacs, L.: 3-Substituted xanthines as promising candidates for quadruplex formation: computational, synthetic and analytical studies. New J. Chem. 35, 476-482 (2011) 
11. Mezzache, S., Alves, S., Paumard, J. P., Pepe, C., Tabet, J. C.: Theoretical and gas-phase studies of specific cationized purine base quartet. Rapid Commun. Mass Sp. 21, 1075-1082 (2007)

12. Sen, D., Gilbert, W.: Formation of parallel four-stranded complexes by guanine-rich motifs in DNA and its implications for meiosis. Nature 334, 364-366 (1988)

13. Low, J. N., Tollin, P., Brand, E., Wilson, C. C.: Structure of 3-methylxanthine. Acta Crystallogr. C42, 1447-1448 (1986)

14. Geraets, L., Moonen, H. J., Wouters, E. F., Bast, A., Hageman, G. J.: Caffeine metabolites are inhibitors of the nuclear enzyme poly(ADP-ribose)polymerase-1 at physiological concentrations. Biochem. Pharmacol. 72, 902-910 (2006)

15. Orlando, R., Padrini, R., Perazzi, M., De Martin, S., Piccoli, P., Palatini, P.: Liver dysfunction markedly decreases the inhibition of cytochrome P450 1A2-mediated theophylline metabolism by fluvoxamine. Clin. Pharmacol. Ther. 79, 489-499 (2006)

16. Zydron, M., Baranowski, J., Baranowska, I.: Separation, pre-concentration, and HPLC analysis of methylxanthines in urine samples. J. Sep. Sci. 27, 1166-72 (2004)

17. Song, J., Park, K. U., Park, H. D., Yoon, Y., Kim, J. Q.: High-throughput liquid chromatographytandem mass spectrometry assay for plasma theophylline and its metabolites. Clin. Chem. 50, 2176-2179 (2004)

18. Rasmussen, B. B., Brosen, K.: Determination of theophylline and its metabolites in human urine and plasma by high-performance liquid chromatography. J. Chromatogr. B 676, 169-174 (1996)

19. Safranow, K., Machoy, Z.: Simultaneous determination of 16 purine derivatives in urinary calculi by gradient reversed-phase high-performance liquid chromatography with UV detection. J. Chromatogr. B 819, 229-235 (2005)

20. Hardin, C. C., Henderson, E., Watson, T., Prosser, J. K.: Monovalent cation induced structural 
transitions in telomeric DNAs: G-DNA folding intermediates. Biochemistry 30, 4460-4472 (1991)

21. Yurenko, Y. P., Novotny, J., Sklenar, V., Marek, R.: Exploring non-covalent interactions in guanine- and xanthine-based model DNA quadruplex structures: a comprehensive quantum chemical approach. Phys. Chem. Chem. Phys. 16, 2072-2084 (2014)

22. Ferreira, R., Marchand, A., Gabelica, V.: Mass spectrometry and ion mobility spectrometry of Gquadruplexes. A study of solvent effects on dimer formation and structural transitions in the telomeric DNA sequence d(TAGGGTTAGGGT). Methods 57, 56-63 (2012)

23. Rosu, F., Gabelica, V., Poncelet, H., De Pauw, E.: Tetramolecular G-quadruplex formation pathways studied by electrospray mass spectrometry. Nucleic Acids Res. 38, 5217-5225 (2010)

24. Baker, E. S., Bernstein, S. L., Bowers, M. T.: Structural characterization of G-quadruplexes in deoxyguanosine clusters using ion mobility mass spectrometry. J. Am. Soc. Mass Spectrom. 16, 989-997 (2005)

25. Paragi, G., Kovacs, L., Kupihar, Z., Szolomajer, J., Penke, B., Guerra, C. F., Bickelhaupt, F. M.: Neutral and positively charged new purine tetramer structures: a computational study of xanthine and uric acid derivatives. New J. Chem. 35, 119-126 (2011)

26. Mautjana, N. A., Looi, D. W., Eyler, J. R., Brajter-Toth, A.: Sensitivity of positive ion mode electrospray ionisation mass spectrometry (ESI MS) in the analysis of purine bases in ESI MS and on-line electrochemistry ESI MS (EC/ESI MS). Electrochim. Acta 55, 52-58 (2009)

27. Eiceman, G. A., Karpas, Z.: Ion Mobility Spectrometry (2nd ed.). CRC Press, Boca Raton, (2005)

28. Shvartsburg, A. A.: Differential ion moblity spectrometry: Non-linear ion transport and fundamentals of FAIMS. CRC Press, Boca Raton (2009)

29. Kolakowski, B. M., Mester, Z.: Review of applications of high-field asymmetric waveform ion mobility spectrometry (FAIMS) and differential mobility spectrometry (DMS). Analyst 132, 842- 
$864(2007)$

30. Guevremont, R.: High-field asymmetric waveform ion mobility spectrometry: A new tool for mass spectrometry. J. Chromatogr. A 1058, 3-19 (2004)

31. Shvartsburg, A. A., Li, F., Tang, K., Smith, R. D.: High-resolution FAIMS using new planar geometry analyzers. Anal. Chem. 78, 3706-3714 (2006)

32. Shvartsburg, A. A., Smith, R. D., Wilks, A., Koehl, A., Ruiz-Alsonso, D., Boyle, B.: Ultrafast differential ion mobility spectrometry at extreme electric fields in multichannel microchips. Anal. Chem. 81, 6489-6495 (2009)

33. Brown, L. J., Toutoungi, D. E., Devenport, N. A., Reynolds, J. C., Kaur-Atwal, G., Boyle, P., Creaser, C. S.: Minaturized ultra high field asymmetric waveform ion mobility spectrometry combined with mass spectrometry for peptide analysis. Anal. Chem. 82, 9827-9834 (2010)

34. Rorrer, L. C., Yost, R. A.: Solvent vapor effects in planar high-field asymmetric waveform ion mobility spectrometry: Solvent trends and temperature effects. Int. J. Mass Spectrom. 378, 336$346(2015)$

35. Smith, R. W., Reynolds, J. C., Lee, S., Creaser, C. S.: Direct analysis of potentially genotoxic impurities by thermal desorption-field asymmetric waveform ion mobility spectrometry-mass spectrometry. Anal. Methods 5, 3799-3802 (2013)

36. Brown, L. J., Smith, R. W., Toutoungi, D. E., Reynolds, J. C., Bristow, A. W. T., Ray, A., Sage, A., Wilson, I. D., Weston, D. J., Boyle, B., Creaser, C. S.: Enhanced analyte detection using insource fragmentation of field asymmetric waveform ion mobility spectrometry - selected ion in combination with time-of-flight mass spectrometry. Anal. Chem. 84, 4095-4103 (2012)

37. Smith, R. W., Cox, L. B., Yudin, A., Reynolds, J. C., Powell, M., Creaser, C. S.: Rapid determination of $\mathrm{N}$-methylpyrrolidine in cefepime by combining direct infusion electrospray ionisation-time-of-flight mass spectrometry with field asymmetric waveform ion mobility spectrometry. Anal. Methods 7, 34-39 (2015) 
38. Menlyadiev, M. R., Tarassov, A., Kielnecker, A. M., Eiceman, G. A.: Tandem differential mobility with ion dissociation in air at ambient pressure and temperature. Analyst 140, 2995-3002 (2015)

39. “MATLAB, Release 2014a," The MathWorks, Inc., Natick, Massachusetts, (2014)

40. Guevremont, R., Purves, R. W.: High field asymmetric waveform ion mobility spectrometry-mass spectrometry: An investigation of leucine enkephalin ions produced by electrospray ionization. J. Am. Soc. Mass Spectrom. 10, 492-501 (1999)

41. Brown, L. J., Creaser, C. S.: Field asymmetric waveform ion mobility spectrometry analysis of proteins and peptides: a review. Curr. Anal. Chem. 9, 192-198 (2013) 


\section{Legends for figures}

Structure 1 Proposed structure of 3-MX non-covalently bound tetramer $\left(\left[(3-\mathrm{MX})_{4}+\mathrm{Cat}\right]^{+}\right)$with stabilising cation $\left(\mathrm{cat}^{+}=\mathrm{NH}_{4}^{+}, \mathrm{Na}^{+}\right.$or $\left.\mathrm{K}^{+}\right)[10,12,13]$

Figure 1 (a) Mass spectrum of 3-MX in $60: 40 \mathrm{MeOH}: \mathrm{H}_{2} \mathrm{O}$ with $1 \mathrm{mM}$ ammonium acetate with FAIMS off; inserts show zoomed in regions of the spectra: (b) a mixture of singly and doubly charged species in the region $m / z 2010-2060$, (c) doubly charged species in the region $\mathrm{m} / \mathrm{z} 1012$ 1040, (d) doubly and multiply charged species in the region $\mathrm{m} / \mathrm{z}$ 1680-1760; (e) mass spectrum of 3 MX in $60: 40 \mathrm{MeOH}: \mathrm{H}_{2} \mathrm{O}$ with $1 \mathrm{mM}$ sodium hydroxide with FAIMS off

Figure 2 ESI-FAIMS-MS analysis of $[(3-\mathrm{MX})+\mathrm{Na}]^{+}(\mathrm{m} / \mathrm{z} 189.04)$ at three different $\mathrm{MS}$ fragmentor voltages: (a) overlaid CF spectra at DF $200 \mathrm{Td}$ where the black solid line $=[(3-\mathrm{MX})+\mathrm{Na}]^{+}$at $150 \mathrm{~V}$, grey dotted line $=[(3-\mathrm{MX})+\mathrm{Na}]^{+}$at $100 \mathrm{~V}$, grey solid line $=[(3-\mathrm{MX})+\mathrm{Na}]^{+}$at $50 \mathrm{~V}$, black dotted line $=$ $\left[(3-\mathrm{MX})_{2}+\mathrm{Na}\right]^{+}(\mathrm{m} / \mathrm{z} 355.09)$ at $150 \mathrm{~V}$; three-dimensional heat maps of DF vs. CF (where intensity (\%) is represented on the colour scale) of (b) $\mathrm{m} / \mathrm{z} 189.04$ at $150 \mathrm{~V}$, (c) $\mathrm{m} / \mathrm{z} 189.04$ at $100 \mathrm{~V}$, and (d) $\mathrm{m} / \mathrm{z} 189.04$ at $50 \mathrm{~V}$

Figure 3 (a) CF spectra at DF 323 Td for singly charged sodium doped tetrameric 3-MX complexes: black solid line $=\left[(3-\mathrm{MX})_{4}+\mathrm{Na}\right]^{+}\left(m / z\right.$ 687.18), black dotted line $=\left[(3-\mathrm{MX})_{8}+\mathrm{Na}\right]^{+}(\mathrm{m} / \mathrm{z} 1351.38)$, grey solid line $=\left[(3-\mathrm{MX})_{12}+2 \mathrm{Na}-\mathrm{H}\right]^{+}(\mathrm{m} / z$ 2037.55); three-dimensional heat maps of DF vs. CF (where intensity (\%) is represented on the colour scale) of (b) $\left[(3-\mathrm{MX})_{4}+\mathrm{Na}\right]^{+}(\mathrm{m} / \mathrm{z} 687.18)$ and $(\mathbf{c})[(3-$ $\left.\mathrm{MX})_{12}+2 \mathrm{Na}-\mathrm{H}\right]^{+}(\mathrm{m} / \mathrm{z} 2037.55)$

Figure 4 Overlapping charge state separation of 3-MX $\left(+\mathrm{Na}^{+}\right)$complexes at fragmentor voltage of $150 \mathrm{~V}$ : three-dimensional heat maps of DF vs CF (with intensity (\%) represented on the colour 
scale) of (a) $m / z 1351.38\left(\left[(3-\mathrm{MX})_{8}+\mathrm{Na}\right]^{+}\right)$and (b) $m / z 1362.38\left(\left[(3-\mathrm{MX})_{16}+3 \mathrm{Na}-\mathrm{H}\right]^{2+}\right) ;(\mathbf{c})$ mass spectrum with no FAIMS; (d) FAIMS CF scan at DF $323 \mathrm{Td}$, selected ion responses for $\mathrm{m} / \mathrm{z}$ 1373.37; (e) FAIMS selected mass spectrum of singly charged species at DF $323 \mathrm{Td}$, CF 1.7 Td; and (f) FAIMS selected mass spectrum of doubly charged species at DF $323 \mathrm{Td}, \mathrm{CF} 2.85 \mathrm{Td}$; (g) three-dimensional heat map of $m / z$ vs. CF (at DF $323 \mathrm{Td}$, with intensity (\%) represented on the colour scale) showing the FAIMS separation of two isobaric species at $m / z 1373.37$, [(3-MX $)_{8}+2 \mathrm{Na}-$ $\mathrm{H}]^{+}$and $\left[(3-\mathrm{MX})_{16}+4 \mathrm{Na}-2 \mathrm{H}\right]^{2+}$, and their isotopic patterns; (f) three-dimensional heat map of DF vs CF (with intensity (\%) represented on the colour scale) of $m / z 1373.37\left(\left[(3-\mathrm{MX})_{8}+2 \mathrm{Na}-\mathrm{H}\right]^{+}\right.$and [(3$\left.\mathrm{MX})_{16}+4 \mathrm{Na}-2 \mathrm{H}\right]^{2+}$

Figure 5 ESI-FAIMS-MS analysis of $\mathrm{m} / \mathrm{z}$ 1019.28: (a) mass spectrum with no FAIMS applied; (b) FAIMS CF scan at DF 216 Td for $m / z 1019.28$ (solid line) and $m / z 1019.78$ (dotted line); (c) FAIMS selection of singly charged species (DF 216 Td, CF 0.25 Td); and (d) FAIMS selection of doubly charged species (DF $216 \mathrm{Td}$, CF $1.10 \mathrm{Td}$ )

Figure 6 ESI-FAIMS-MS analysis of a hetero-cation $\left[(3-\mathrm{MX})_{16}+2 \mathrm{Na}+\mathrm{K}-\mathrm{H}\right]^{2+}$ of $\mathrm{m} / \mathrm{z}$ 1370.36: (a) FAIMS CF scan at DF 323 Td; (b) mass spectrum with no FAIMS applied; (c) FAIMS selection at CF $1.65 \mathrm{Td}$; (d) FAIMS selection at CF $2.75 \mathrm{Td}$ 


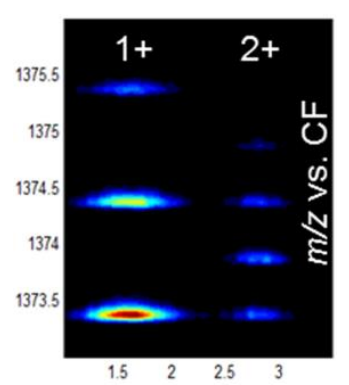

Graphical Abstract

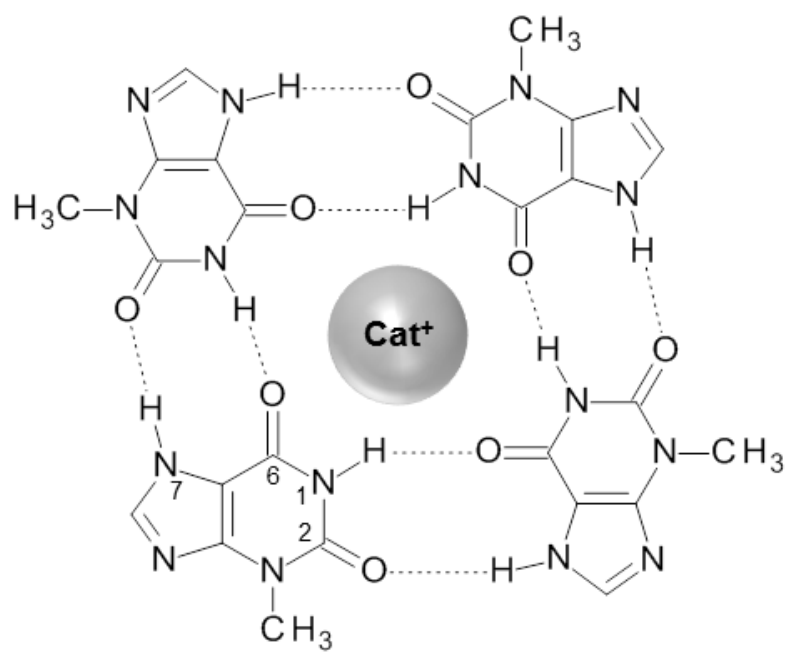

Structure 1 
(a)

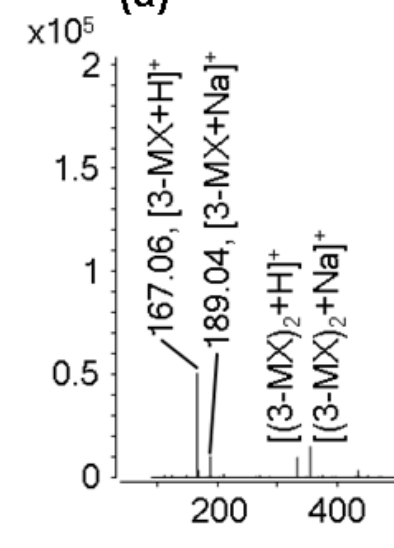

$\left[(3-\mathrm{MX})_{4}+\mathrm{Na}\right]^{+}$

687.19

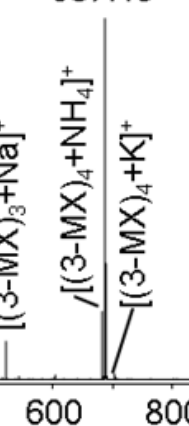

$\times 10^{2} \quad\left[(3-\mathrm{MX})_{12}+2 \mathrm{Na}-\mathrm{H}\right]^{+}$

(b) 2037.57

1016.81

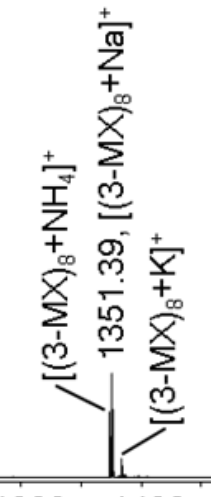

$\frac{1694.98-2037.57}{1600 \mid 18002000 \quad 2200}$ Counts vs. $m / z$
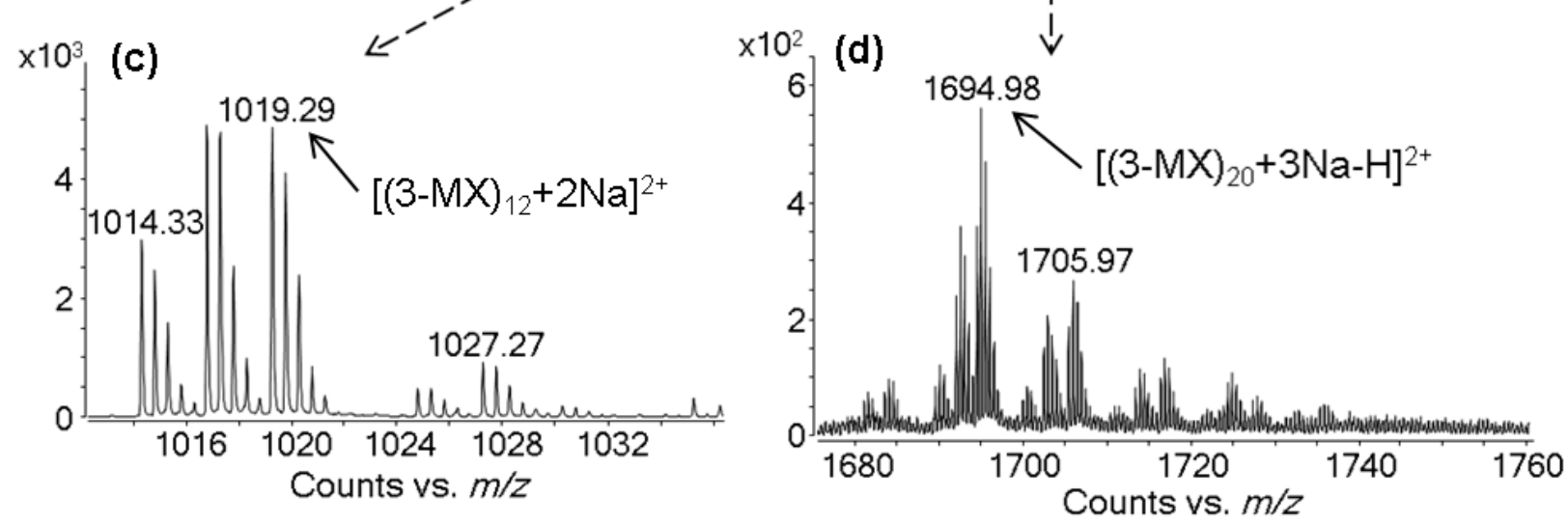

Figure 1 

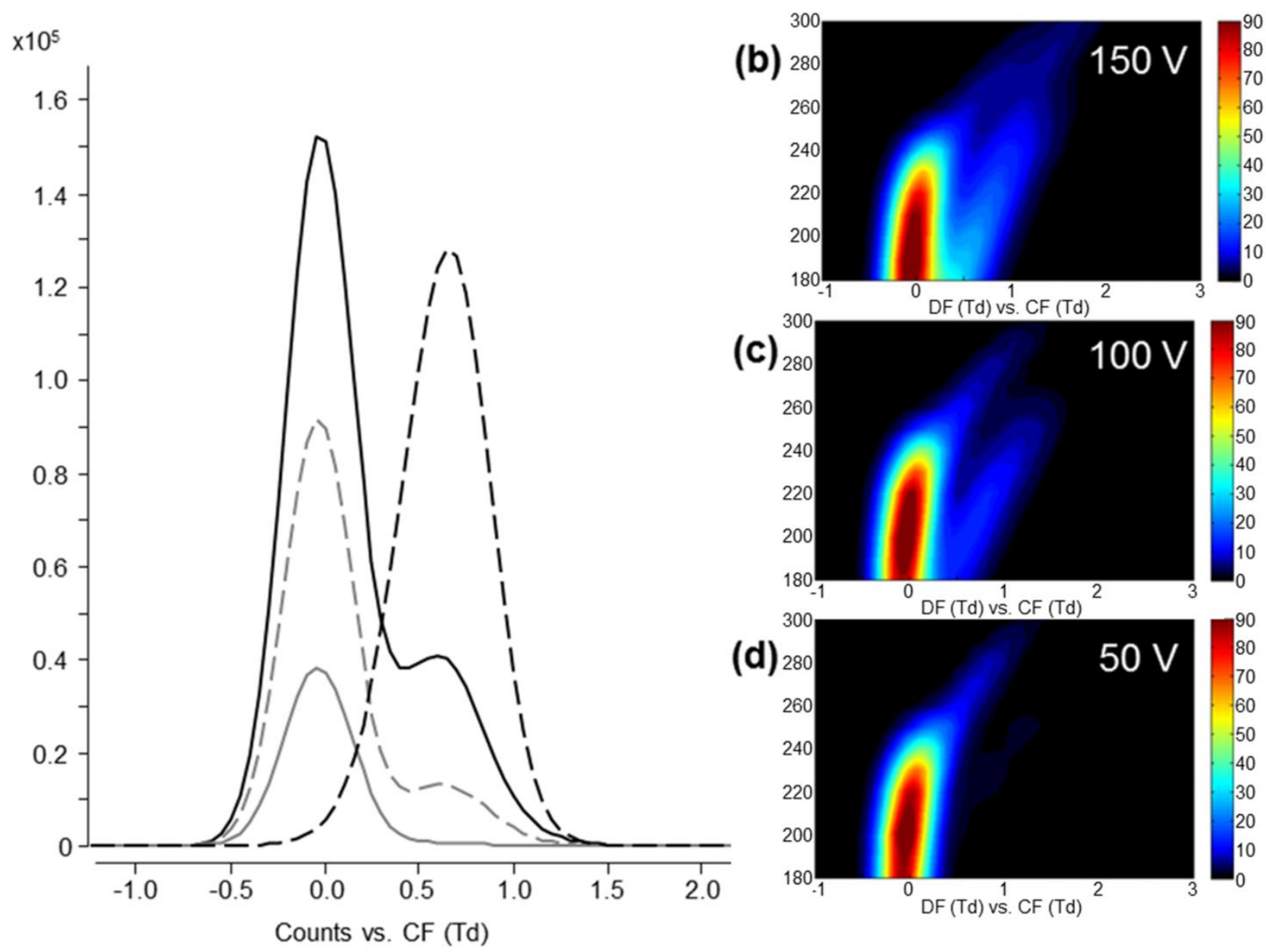

Figure 2 


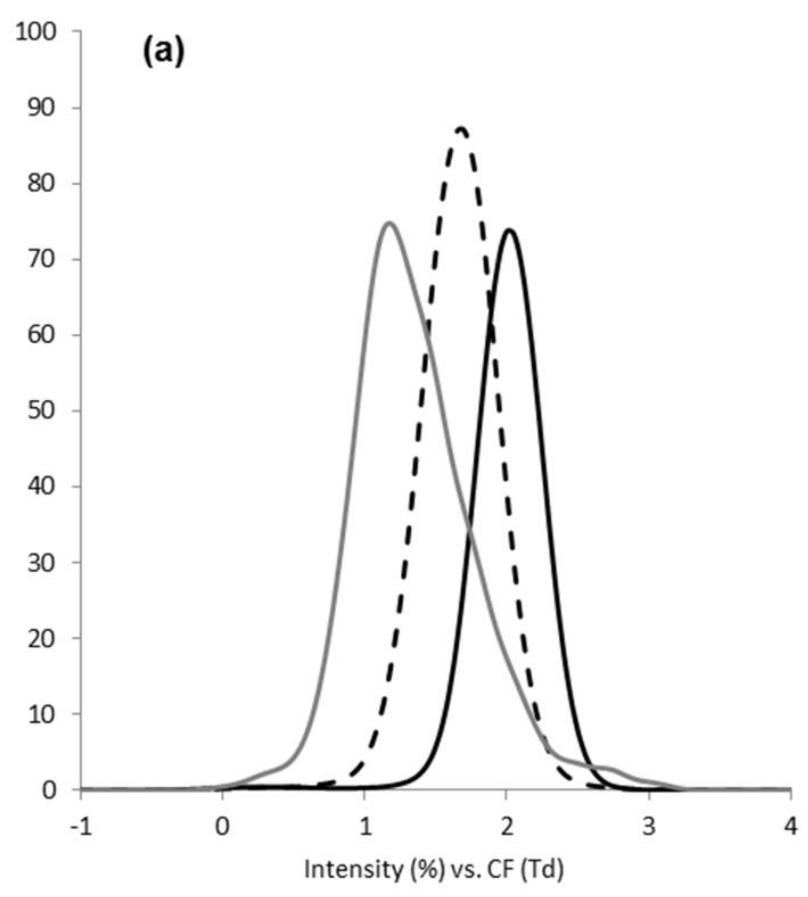

(b)
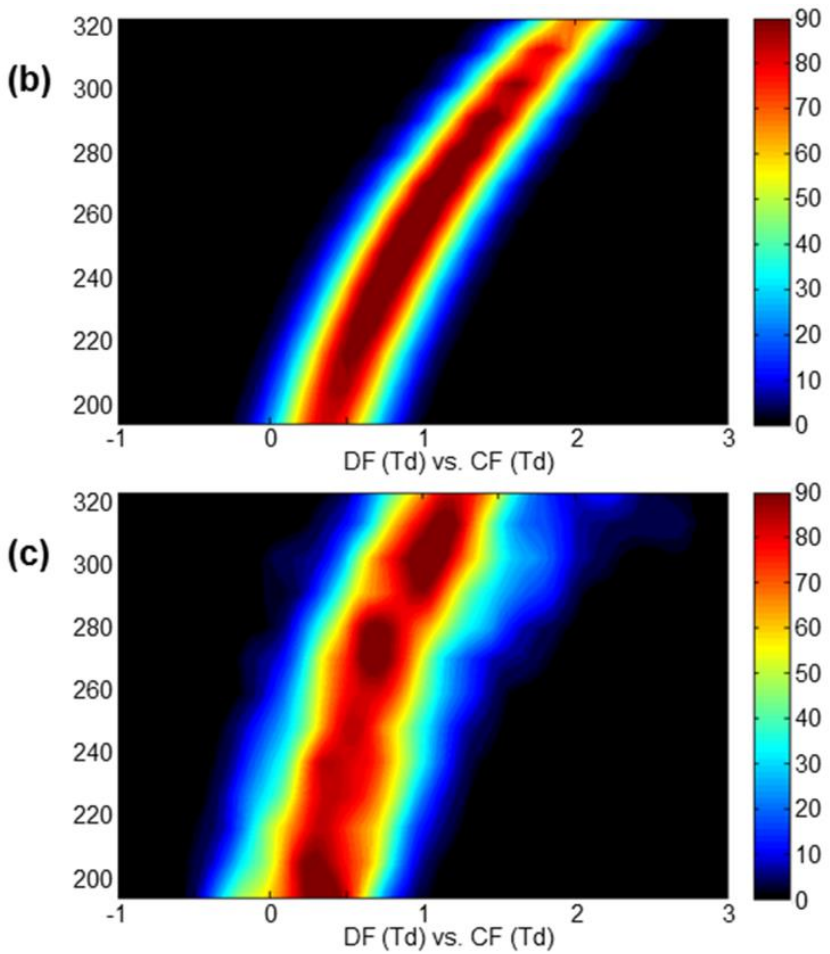

Figure 3 

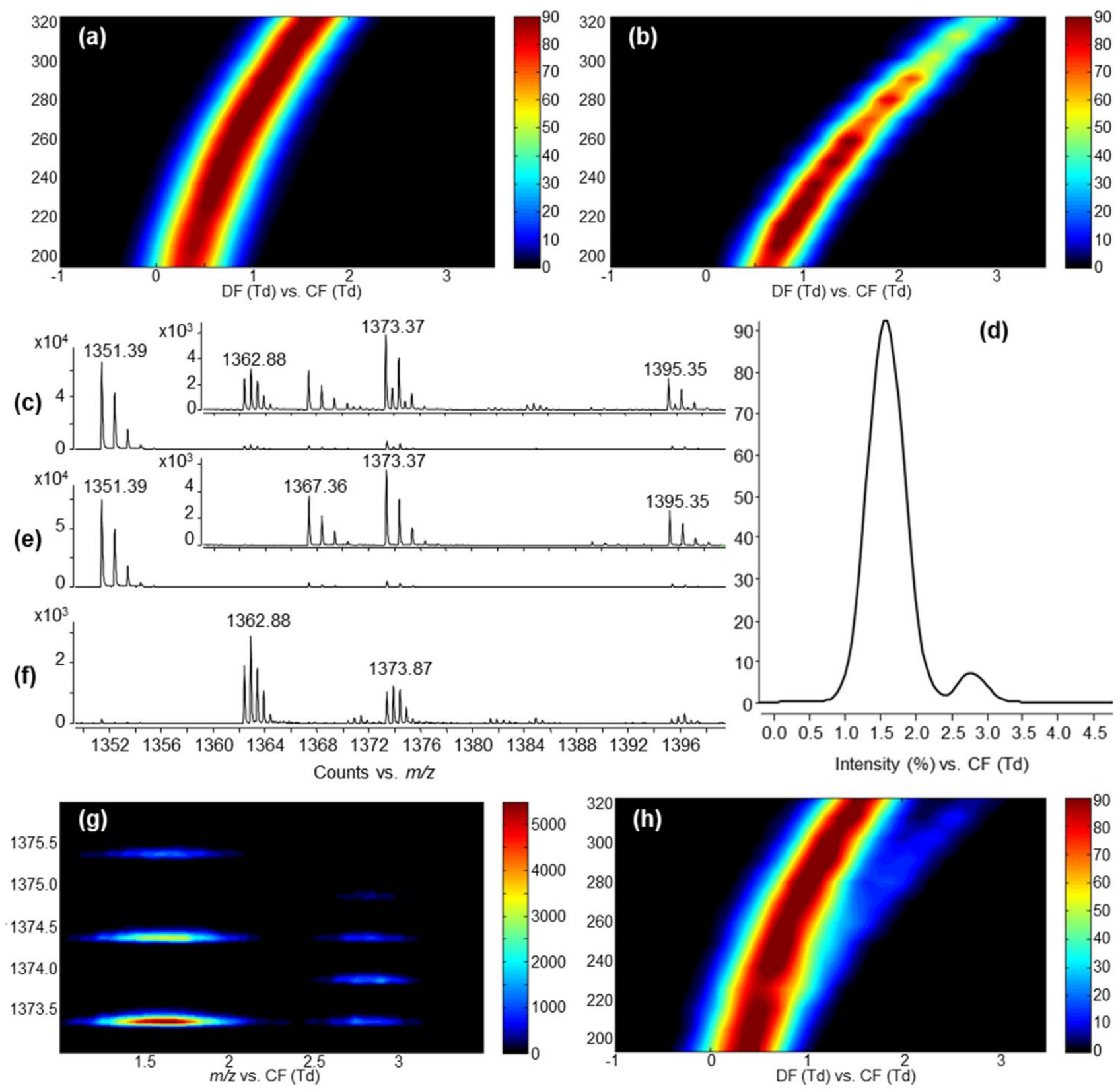

Figure 4 

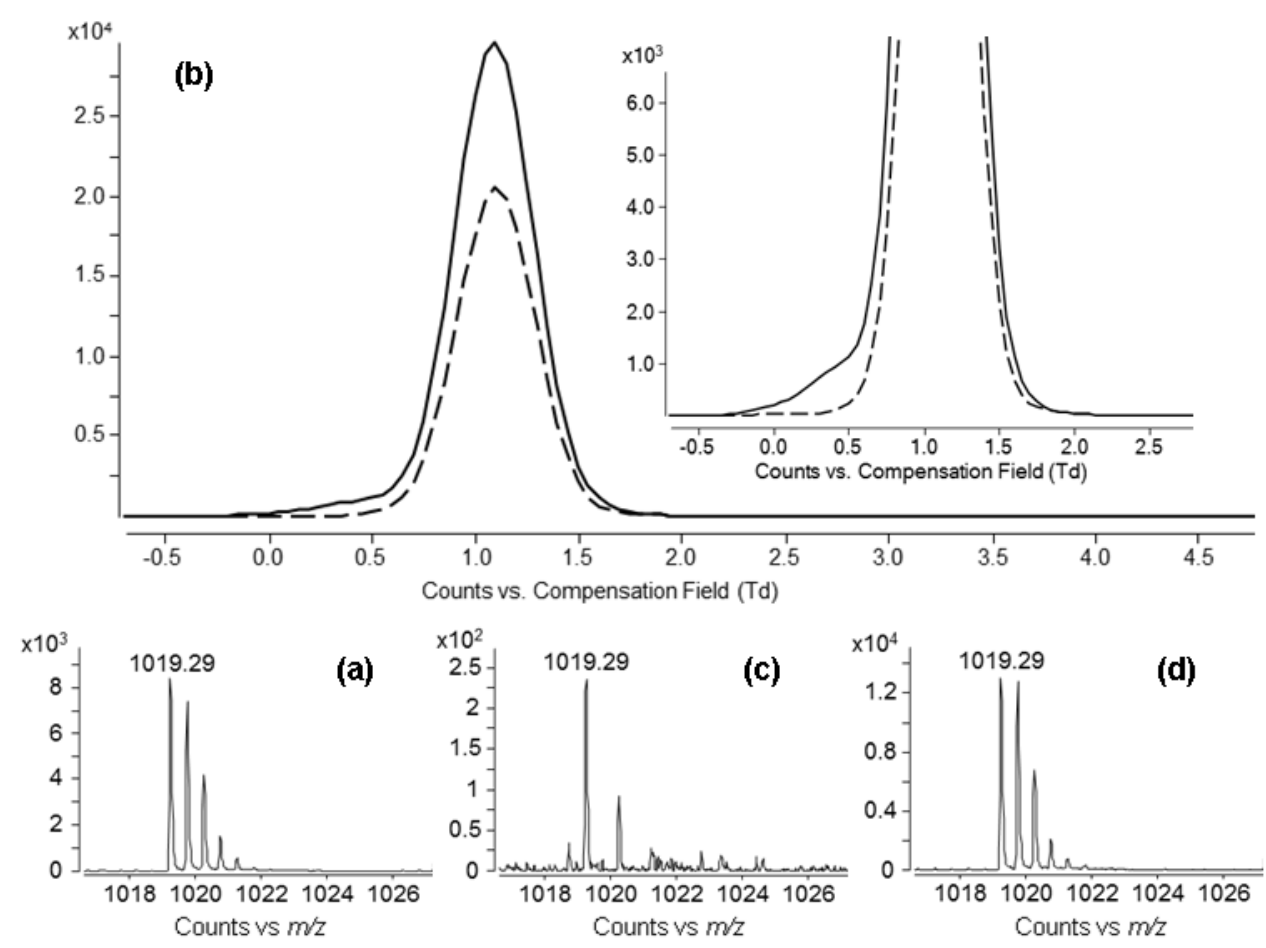

Figure 5
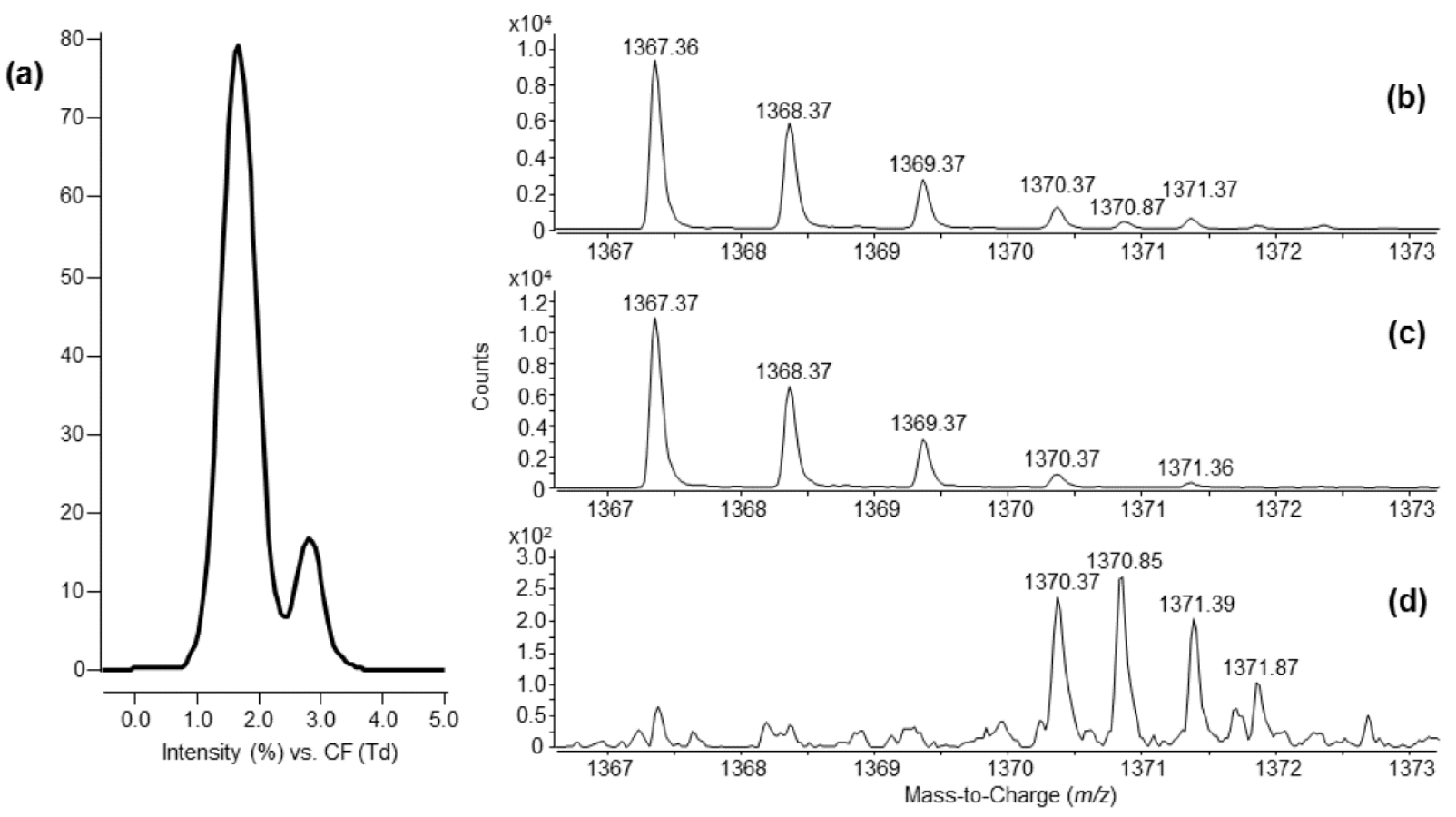

Figure 6 